\title{
The Anti-Vaccination Debate: A Cross-Cultural Exploration of Emotions and Epistemic Cognition
}

\author{
Ayano Tsuda \\ Department of Educational and Counselling Psychology, \\ McGill University, Montreal, Canada. \\ Krista R. Muis \\ Department of Educational and Counselling Psychology, \\ McGill University, Montreal, Canada.
}

\section{Author Notes:}

Support for this research was provided by grants to Krista R. Muis from the Social Sciences and Humanities Research Council of Canada (435-2014-0155) and the Canada Research Chairs program.

\begin{abstract}
Do vaccines cause autism? Answers to this question have become hotly debated since Web 2.0, where self-authored content continues to grow. If individuals do not have the skills to judge the veracity of information, this can have negative health consequences. Equally troubling is the negative emotions that arise due to the content on vaccination websites, which can be detrimental for learning . We examined source and justification strategies authors used in vaccine websites from USA, Canada, Japan and Chile, and the epistemic strategies and emotions individuals used or expressed while reacting to website content. Analyses revealed that pro-vaccination websites justified claims using quotes from experts. In contrast, anti-vaccination websites relied on sources from personal experience. Results also indicated that anger was prominent in websites that included a balanced or pro-vaccine view, which was consistent across cultures. These results provide insight into the importance of emotions in learning about controversial topics, and shed light into possible cultural differences in formatting arguments. Results may be used to develop interventions designed to change misconceptions about controversial topics that are emotionally driven.
\end{abstract}

Key words: emotion; epistemic cognition; anti-vaccines; pro-vaccines; cross-cultural comparison

\section{INTRODUCTION}

Do vaccines cause autism? Are childhood vaccinations safe? Answers to these questions have become debated since Web 2.0, where self-authored, unregulated content continues to grow [1]. Unfortunately, although $80 \%$ of Internet users search for health-related information [1], only $45 \%$ of sites about vaccinations are scientifically accurate [2]. If individuals do not have the skills to judge the veracity of information, or assess source quality, this can have negative health consequences by making health-related decisions that are ill-informed. That is, individuals must engage in high-quality epistemic cognition [3].

Equally troubling is the emotional upheaval caused by vaccination websites. A quick scan of comments left on vaccination websites reveals that individuals experience a variety of emotions regarding whether or not to vaccinate. As previous research has shown, emotions facilitate or constrain learning processes and outcomes [4]. For example, negative emotions, 
like anxiety and anger, can limit individuals' ability to critically evaluate information [5]. In contrast, positive emotions, like curiosity and enjoyment, have been shown to foster effortful thinking and flexible learning strategies [6]. Given these issues, research is needed to examine how individuals evaluate claims made on these websites, what emotions arise when individuals read content on these websites, and whether emotions vary as a function of quality and cultural context of the information. That is, to our knowledge, no research has taken into account cross-cultural differences that may arise in epistemic cognition or emotions when reading information about a controversial topic like vaccines. If differences arise, such information would help to inform interventions designed to reduce the negative impact of misinformation on the Internet.

As such, the purpose of this research was to examine individuals' epistemic cognition about website content of varying epistemic quality and perspective, and the emotions individuals expressed while responding to the content or other individuals' comments on those websites. To situate this work, in the ensuing literature review, we delineate persuasive strategies found on the Internet in relation to vaccines, and then present theoretical and empirical work on emotions and epistemic cognition coupled with a literature review on the importance of epistemic cognition when searching information about controversial topics. Lastly, given cultural differences in epistemic cognition [7-9] and emotion expression [10,11], a discussion on cultural considerations of each construct is reviewed.

\section{Persuasive Strategies on the Internet}

Compared to the first generation of the Internet, Web 1.0, wherein websites were static, proprietary, and lacked interactive aspects, Web 2.0 enables a two-way communication where content is contributed by anyone [12]. In other words, Web 2.0 is user-generated with information supported by social media such as Facebook and Twitter, which facilitates health communication among users and eases the spread of information [1]. Unfortunately, information provided in the media does not guarantee its quality, as anyone can contribute to the content. This becomes an issue particularly when the topic is viewed as controversial, such as vaccinations [13].

The vaccine controversy typically is traced back to a study conducted by Wakefield et al. [14] wherein they argued that developmental disorders are linked to the measles, mumps and rubella (MMR) vaccine. Even though the research was fully retracted, this information triggered an anti-vaccination movement, wherein many people around the world still believe that the MMR vaccine causes developmental disorders such as autism [1]. This is particularly problematic in a world where Web 2.0 is widespread, which has allowed individuals without expertise about vaccinations to post information on the Internet.

For example, Kata [15] conducted a Google search on information about vaccinations using terms like "vaccine", "vaccination", and "immunization." Kata found that for websites that provided information about vaccines, $88 \%$ of the claims made were misrepresented. Inaccurate information included, for example, drawing false conclusions from research, or using untruthful sources such as the study by Wakefield et al. [14]. In another study, Kortum et al. [2] examined how effectively high school students in an advanced science class accurately assessed Internet-based health information on vaccines. The students conducted a Google search using terms such as "vaccine safety" and "vaccine danger," and were asked to answer questions related to the accuracy of information on the sites and what they learned about vaccines. Analysis revealed that $67 \%$ of the websites gave inaccurate information about vaccines. Furthermore, they found that $59 \%$ of the students thought that the sites gave 
accurate information and $53 \%$ of the students left the exercise with misconceptions about vaccines.

Betsch, Renkewitz, Betsch, and Ulshöfer [16] found that anti-vaccine websites persuade individuals by drawing on their emotions through personal stories. Personal testimonies, such as narratives of parents who felt their children were affected by the use of vaccines, were the most common emotive appeals used on the internet [15]. As Betsch et al. [16] argued, the use of first person narrative enhances credibility. Results from Kortum et al.'s [2] study support this claim: students reported that inclusion of personal stories on the websites were compelling, whereas sites with authoritative web pages with peer-reviewed material were viewed as less compelling. Furthermore, narratives are also known to be easily understood and are considered as highly emotional [12]. Betsch, Ulshofer, Renkewitz, and Betsch [17] looked at online narrative information and its impact on risk judgments. They found that the more emotional the narrative, the greater the perceived risk of vaccination. These results suggest that anecdotal information presented on the Internet regarding vaccines may influence the decisions and views an individual has towards vaccinations by triggering one's emotions.

\section{Emotions}

Emotions refer to multifaceted phenomena that involve affective, cognitive, physiological, motivational, and expressive components $[18,19]$. For example, a learner may feel anger during learning because the information contradicts his or her opinion. In this case, the rage experienced (affective), discrepancy with one's thought (cognitive), increased heart rate (physiological), impulse to fight the situation (motivation), and lowered slanting eyebrows (expressive) might comprise the learner's feelings of anger. In the field of education, emotions are considered to have profound effects on learners' performance and achievement outcomes [11]. For example, anger has been shown to decrease achievement because it increases taskirrelevant thinking, but the same emotion could also motivate an individual to work harder to overcome obstacles $[5,6]$ ).

One prominent theoretical framework linking emotions to learning processes and outcomes includes Pekrun's $[10,11]$ control-value theory of achievement emotions. According to Pekrun [10], emotions can be grouped based on their valence (positive and negative), degree of arousal (activating and deactivating), and object focus. Valence refers to whether the emotion experienced is pleasant (positive) or unpleasant (negative), whereas degree of arousal refers to physiological activation. As such, emotions can be categorized as positive activating (e.g., enjoyment, curiosity), positive deactivating (e.g., relief), negative activating (e.g., frustration, confusion), or negative deactivating (e.g., boredom).

In terms of object focus, there are at least four distinct groups of emotions, including achievement emotions, topic emotions, epistemic emotions and social emotions [10, 20]. Given their relevance when learning about controversial or contradictory content [21], and the social nature of the websites examined for this research, epistemic emotions and social emotions were considered. Knowledge-related emotions are known as epistemic emotions (e.g., surprise, curiosity, confusion), and arise when incoming information is inconsistent with prior knowledge, beliefs, or recently processed information [21]. Social emotions refer to emotions that individuals experience in a social context (e.g., envy, jealousy, schadenfreude, anger toward others) [6]. For instance, frustration a learner experiences when attempting to learn two scientific theories that contradict each other is considered an epistemic emotion if the focus is on the cognitive incongruity caused by the contradiction. If other individuals are involved in the experiencing of emotions, such as admiration or hate towards others, the emotion is considered a social emotion. 


\section{Emotions and science learning}

In a time when there are complex and dynamic issues surrounding the understanding of science [22], it is important to identify which emotions arise during science learning. In addition, with new advances in technology, the learning environment is not limited to a classroom context; learning through other mediums like the Internet must also be taken into consideration [23]. Given the interactive environment of Web 2.0, it is particularly important to consider the type of emotions, like social emotions, that are experienced during learning in social contexts.

For example, Linnenbrink-Garcia, Rogat and Koskey [24] conducted a study exploring the social emotions that emerge during small-group activities. Of particular interest, they found reciprocity between group interactions and emotions whereby negative group interactions, such as disengagement from the group, were related to negative emotions, such as boredom. However, positive emotions, like excitement, and positive interactions, like engagement promoted by others, were found to interrupt the negative interactions. In the context of the Internet and vaccines, Betsch et al. [16] examined features of narratives that impacted risk judgments on vaccines. They found that high emotional narratives had a greater impact on the perceived risk, which in turn decreased vaccination intentions.

With regard to epistemic emotions, empirical studies have shown that negative epistemic emotions, such as confusion, motivate learners to reduce the incongruity between one's original belief and newly acquired information [25]. To reduce the incongruity, individuals may use resolution strategies, but if the discrepancy is too large, individuals may simply ignore the conflicting information [21]. For example, Trevors, Muis, Pekrun, Sinatra, and Winne [26] explored relations between epistemic emotions and knowledge revision. Of particular relevance, individuals who believed that genetically modified foods were not pure and who stated that dietary purity was an important part of their self-concept experienced more negative emotions than individuals who did not hold these same beliefs. These negative emotions then interfered with knowledge acquisition and revision of individuals' attitudes towards and misconceptions about genetically modified foods. As such, negative epistemic emotions might conflict with learning and decision-making when acquiring new knowledge that is inconsistent with their prior knowledge.

In relation to vaccines, Nyhan, Reifler, Richey, and Freed [27] examined the effectiveness of health messages in reducing misconceptions of the MMR vaccine and its link to autism for parents with children younger than 17 years of age. They found that health narratives that induced fear increased self-reported belief in vaccine safety concerns, such as serious side effects. As previously noted, narratives are the most commonly used tactic in vaccine-related websites (e.g. [15]). However, not much focus has been given on the emotions that individuals voluntarily express on these websites in the context of responding to the content or others' comments. Moreover, to date, research has not considered whether there are differences in expressed emotions with regard to the position that the various websites take on whether or not to vaccinate. That is, it may be the case that websites that provide scientifically accurate information (e.g., Centers for Disease Control) trigger different emotions compared to websites that present misinformation about vaccinations (e.g., anti-vaccination websites that focus on faulty consequences of vaccinations like autism). Of particular concern, negative activating emotions, like anger, may result in individuals not being able to accurately judge the veracity of information presented on misinformed websites or may result in individuals ignoring information on websites that present accurate information if they already hold misconceptions about vaccines. That is, emotions may facilitate or constrain high-quality epistemic cognition [21]. 


\section{Epistemic Cognition}

Epistemic cognition is defined as thinking about the epistemic characteristics of information, including knowledge claims and their sources, as well the enactment of epistemic strategies and processes for reasoning about that information, its sources and knowledge claims [3], More broadly, the field of personal epistemology includes the study of individuals' thinking about knowledge and knowing, which has focused primarily on epistemic beliefs, or individuals' beliefs about knowledge and knowing $[7,28]$.

One prominent theoretical framework within the personal epistemology literature is Hofer and Pintrich's [7] framework. According to Hofer and Pintrich [7], there are two dimensions that reflect the nature of knowledge that vary along a continuum from less constructivist to more constructivist: 1) certainty of knowledge, that is, the degree to which one sees knowledge as fixed or evolving, and 2) simplicity of knowledge, or the degree to which knowledge is seen as isolated bits and pieces of information or interrelated. The other two dimensions fall under the nature of knowing: 3) source of knowledge that ranges from knowledge originating from outside the self, such as authority, to knowledge constructed by the individual through active construction and interaction with the environment, and 4) justification for knowing, which ranges from a blind reliance on authorities to justify knowledge claims to individuals evaluating knowledge claims via the use of evidence and by integrating and comparing multiple sources of information.

Epistemic cognition is known to play an important role when dealing with scientific information, especially with contradictory information and how well people integrate prior knowledge and different sources of information to create a coherent representation of the scientific issue [13]. Moreover, reading multiple sources, which is necessary when searching for information on the Internet, requires the skill to locate relevant information as well as the ability to assess the epistemic aspects of the information [29]. That is, individuals must assess the credibility of the source, and determine whether the information provided is validly justified. As such, epistemic cognitive processes across the four dimensions of knowledge and knowing become important when one is faced with a controversial topic via the Internet where there is no guarantee of the quality of information and the readers themselves must evaluate the truthfulness of that information [23].

For example, Mason, Boldrin, and Ariasi [30] captured epistemic cognitive processes using a think aloud protocol as university students searched the Internet for information about dinosaur extinction. They found that all participants spontaneously expressed epistemic cognitive processes that related to the four dimensions of knowledge and knowing. In particular, of all epistemic cognitive processes captured, $67.33 \%$ reflected a judgment about the source of knowledge, and $16.44 \%$ reflected evaluations with regard to the justification of knowledge. For example, for justification of knowledge, common epistemic cognitive processes that participants used included judgments as to whether information was consistent or not with their own knowledge (66.6\%), followed by evaluations of scientific evidence (28.6\%). They also noted that almost all of the participants recognized the partisan websites but only a few of the participants substantiated their claim with scientific evidence.

Additionally, several researchers have found that learners who believe knowledge is complex and evolving consider conflicting information more thoroughly and spend more time on reliable sources compared to those who believe that knowledge is simple and certain [9]. These differences in beliefs about knowledge result in better learning gains on the tasks for those with more constructivist beliefs [9]. For instance, Mason, Pluchino, and Ariasi [31] used an eye-tracking device to assess differences in what university students attend to as a function 
of their epistemic beliefs. They found that those who believed in complex knowledge fixated more on graphical information on the websites, indicating more critical evaluation of the information.

With regard to source and justification, Yang, Chen, and Tsai [32] explored the judgment criteria used by university students in Taiwan on socio-scientific issues. They found that these students paid attention to various aspect of the content searched, such as sophistication of the arguments, and checked the authoritativeness of the source. Furthermore, the relationship between students' epistemic beliefs and their use of justification strategies indicated that the less they believed in relying solely on authority as the source of knowledge, the more critical their criteria for the evaluation of arguments.

Sinatra and colleagues (e.g., [33-35]) have further argued that when learning about controversial science topics, individuals' attitudes must also be taken into consideration. Eagly and Chaiken [36] define attitude as an evaluation of an object, such as the extent to which one dislikes or likes the attitude object, or the extent to which one favors or disfavors the entity that is evaluated. Based on this notion, Sinatra and Seyranian [35] suggest that when attitudes are based on misconceptions, for instance having an anti-vaccination attitude based on the misconception that vaccines are related to autism, their misconceptions are particularly resistant to change unless attitudes are corrected.

Taken together, results from these studies suggest that in an era where information can be easily searched on the Internet, there is more responsibility on each individual to compare and contrast different web pages and justify their arguments, which becomes a challenge with abundant information on the Internet. It is clear that misinformation places additional burden on individuals when searching for information on the web. Moreover, depending on the attitude one has towards the controversial topic, it may affect the extent to which they change, or not change, the misconceptions that they have. There is a necessity for them to think critically about the content and to filter information accordingly. However, not much is known regarding the quality of sourcing and justification across websites of varying perspectives. Furthermore, contexts are known to matter in regard to the relation between epistemic cognition and the Internet [37]. That is, given cultural differences in emotional expression and epistemic cognition, cultural differences need to be taken into consideration [9].

\section{Cultural Aspects}

Both emotion and epistemic cognition are found in every culture; however, the process and their contents, as well as the extent to which they are present in each culture differ $[8,11]$. In this section, a brief overview of possible cultural differences and aspects of their universality are discussed in relation to emotive and epistemic cognitive components.

\section{Emotions}

With regard to emotions, Pekrun and Perry [11] proposed that there is universality in terms of functional mechanisms. For example, principles linking emotions with their antecedents and outcomes are proposed to be universal. However, the frequency of the occurrence, contents and process of the emotion including its intensity varies depending on one's culture [11]. Research has shown that European Americans show more positive emotions than negative ones compared to Chinese Americans when discussing areas of conflict with their partners [38]. This is consistent with other research that states Western cultures express more positive emotions to differentiate themselves positively from others [39]. On the other hand, researchers have shown that the opposite is also true. Studies in educational contexts, comparing Germany and China, have found that Chinese students experienced higher levels of 
enjoyment, pride and shame towards mathematics, whereas German students experienced higher levels of anger [40]. Individuals from collectivistic cultures, such as China, are known to display lower frequency of intense emotions such as anger depending on the severity of the problem, either academic or social [41]. These differences in emotional experiences and expressiveness might be important to consider in relation to Web 2.0, which may be traced via the comments that individuals leave on websites about vaccines.

\section{Epistemic cognition}

Personal epistemology is socially constructed [42]. Cross-cultural studies focusing on dimensions of epistemic cognition have found that Asian cultures show respect and obedience towards authority figures [43]. In North America, critical thinking is valued and is a common objective in Western education [44]. Therefore, thinking for oneself and making independent choices may be considered important in Western cultures, whereas in Asian cultures, authoritativeness might play an important role when defining their beliefs about knowledge and knowing. For example, Hofer [45] found that the structure of the four dimensions of epistemic cognition (certainty, simplicity, source, and justification) was supported crossculturally but there were also cultural differences among US and Japanese students. Result indicated that US students were more constructivist in their beliefs across all four dimensions. Japanese students, on the other, were found to show respect to authority figures and held a stronger belief in the certainty and simplicity of knowledge.

Strømsø, Bråten, Anmarkrud, and Ferguson [46] also found cultural differences in individuals' epistemic cognition, specifically in the justification of knowledge. They contrasted ethnic majority and ethnic minority high school students in Norway. Ethnic minority students consisted of families where neither parent spoke Norwegian as their first language, and were from Europe, Asia and Slavic-speaking communities, whereas ethnic majority students were native Norwegian speakers. In the domain of scientific learning and understanding, ethnic minority students believed knowledge claims can be justified by appealing to scientific authorities, which facilitated learning and comprehension while no such comparison was found among ethnic majority students. These sharp contrasts are, however, decreased when the cultures are similar [8]. Given these cultural differences, we questioned whether the content on the various websites in addition to individuals' comments would vary as a function of culture across the four epistemic dimensions. We describe our specific research questions and hypotheses next.

\section{Research Questions and Hypotheses}

The objectives of this research were to analyze various vaccination websites in terms of the quality of the claims made about vaccinations as a function of perspective (i.e., pro vaccine, anti-vaccine, or neutral) and culture (Western versus Eastern). Websites from cultures that vary in emotional expression by country were chosen, which were the United States and Canada, Japan and Chile [47]. In addition, we explored whether individuals' expressed emotions and epistemic cognition about the content varied as a function of website perspective, attitude toward vaccinations, and culture.

For each website, we first examined the emotions prevalent in each of the websites across cultures as a function of website attitude (pro- or anti-vaccine). Our research questions included the following: (1) Are there cultural differences in the extent to which individuals express positive or negative emotions about controversial topics like vaccinations? For collectivistic cultures, given that intense emotions like anger are expressed less often compared to individualistic cultures [41], we hypothesized that there would be less frequency of anger reported in Japan and Chile (collectivistic cultures $[39,48]$ ) compared to the US and 
Canada. For positive emotions, since conflicting results have been reported in previous research [38-40], we do not offer any specific research hypotheses.

We also asked: (2) Are there cultural differences in the extent to which individuals express negative or positive emotions in response to controversial arguments on vaccinations as a function of attitude (pro or con vaccinations)? For emotions and attitudes, we hypothesize that negative emotions, such as anger, might be more prevalent in websites that oppose individuals' attitudes, whereas positive emotions, such as gratitude, might be expressed more often in websites that support their attitudes.

For epistemic cognition, our research question was as follows: (3) Are there differences in the quality of arguments, particularly the sourcing and justification strategies used, on the websites as a function of attitude (pro versus con vaccination) and culture? We examined this question from two perspectives: one from the website itself, and one from individuals' comments provided on the website. For the websites, given that the majority of antivaccination websites rely on personal stories rather than scientifically valid information [2], we hypothesized that the quality of argumentation and justification strategies used for these websites would be poor compared to websites that provided pro-vaccine content. Moreover, since collectivistic cultures respect and value authority [43][45], we hypothesized more reliance on authority for collectivist culture-based websites compared to the individualistic culture-based websites.

For individuals, we took into consideration their attitudes (pro, con or neutral) towards vaccinations to assess whether there were differences in quality of epistemic cognition as a function of culture and website perspective. Due to the exploratory nature of this research, we have no specific hypotheses with regard to quality of individuals' epistemic cognition as a function of attitude and website perspective. We did, however, hypothesize that individuals from collectivist cultures would rely more on authority compared to individuals from individualistic cultures.

The arguments used in the comments of websites were considered from two contrasting cultures: United States and Canada compared to Japan and Chile. Canadian and American cultures share many historical and cultural similarities [49], therefore analysis for Canadian and American websites were combined into one group as North America. Japan and Chile, which are categorized as collectivistic or interdependent cultures, were considered separately as the degree of collectivism is known to differ between Asian and South American culture [48].

\section{Materials}

\section{METHODOLOGY}

We chose websites from cultures that vary in emotional expression by country: United States and Canada, Japan and Chile [47]. Keywords 'vaccines' and 'child' were entered into Google search, a search engine commonly used in past vaccine-related research (e.g. $[2,15,50])$. Popular parental magazine websites were chosen based on whether they presented one or both sides of the debate. Sites were considered anti-vaccine if they advocated refusal of vaccines and/or emphasized vaccine risk [50]. Those that advocated vaccines were categorized as pro-vaccines. Furthermore, one website that included both anti and pro-vaccine views was included for analysis. Since the purpose of the research was to focus on people's reactions to the content of the webpage, it was a requisite to have a section in which people could leave comments. Highest number of shares and visits were also used as criteria in choosing the websites. The websites used in this research were as follows: 
1. The top 6 reasons why parents are choosing not to vaccinate their kids [51] (Canada; balanced view point).

2. 6 reasons to say no to vaccinations [52] (USA; anti-vaccines).

3. 10 vaccine myths busted [53] (USA; pro-vaccines).

4. Sekai no uragawa news [54] (News from the other side of the world; Japanese; antivaccines).

5. Are you against or pro-vaccines? [55] (Japanese; pro-vaccines).

6. Vacunas infantiles: peligrosas e innecesarias [56] (Infant vaccines: dangerous and unnecessary; Chilean; anti-vaccines).

7. Paremos la locura anti-vacunación infantile [57] (Let's stop the insanity of infant antivaccination; Chilean; pro-vaccines).

The comments that viewers of the website wrote were content analyzed for the emotions that were expressed in reaction to the website itself or in reaction to other comments that people wrote. The comments to be analyzed were selected on the same day, March 7, 2016, for all the above websites to avoid any social or political news to affect the standpoint mentioned in the comments. Furthermore, content of the webpage itself was analyzed for quality of the sourcing information and justification for the positions taken.

\section{Coding for Emotions}

Individuals' comments were segmented and then analyzed using a coding scheme that was created for this research. Pekrun's control-value theory of achievement emotions (e.g. [10, 6, 11]), and instruments designed to measure emotions (e.g., Achievement Emotions Questionnaire [5]; Epistemically-Related Emotions Survey [58]) were used as a guide to create the coding scheme, with a specific focus on social and epistemic emotions. Social emotions were coded as emotions that emerged in relation to the interactive nature in the social medium, such as emotions that arise in relation to other people's comments, to the article, or to society in general (for a full list of emotions, their definitions and examples, see Table 1).

Similarly, individuals' reactions to the web content or to other individuals' posts were coded for epistemic emotions. All epistemic emotions were considered, however, the only emotions that were explicitly stated included surprise, confusion, curiosity (which are always epistemic in nature, see [21]), and enjoyment (see Table 2). Once the coding scheme was established, a research assistant unfamiliar with the objective of the research was first trained on the coding scheme, and then coded $10 \%$ of all webpage comments independently. Inter-rater reliability was established at $97.4 \%$ and disagreements were resolved through discussion.

\section{Coding the Epistemic Quality of Websites}

For each website, content was first segmented and then coded for quality of the sources used (i.e., credibility of source) and quality of the justifications made for each claim (i.e., personal anecdote or high-quality scientific evidence). Credibility was coded as strong or weak depending on the source provided. Sinatra et al. [13] have suggested that considering knowledge as absolute and residing only in an external source is a less constructivist view. However, relying on experts as testimony of others with regard to scientific claims is a valid and reliable strategy [59]. As such, sources that included published peer-reviewed articles in reliable journals, and quotes from experts were categorized as strong, or valid and reliable sources, whereas referring to newspaper articles without scientific evidence, sourcing websites such as Wikipedia, having no link to outer resources or no support were categorized as weak, or invalid and unreliable sources (see Table 3). 
Moreover, justification of the claim was also considered, categorized as valid and reliable if from an authority (i.e., medical experts, peer-reviewed articles), or invalid and unreliable if from personal anecdotal narratives or if no support for justification was provided. Additionally, for each source and claim made, quality of source (i.e., highly respected journal, or not) and content of the original source (i.e., original article or validity of quote from expert) was checked to ensure accuracy of each claim made (i.e., whether source was correctly referenced or interpreted). Two raters coded two of the seven websites to establish inter-rater reliability, which was established at 91.0\%. Disagreements were resolved through discussion.

\section{Coding for Epistemic Cognition from Individuals' Comments}

To consider individuals' epistemic cognition, their comments were considered. Using a previously developed coding scheme [30], comments provided by one individual was considered as a whole and was given points on each of the four epistemic dimensions: certainty, simplicity, source, and justification. Points were distributed depending on the level of sophistication of each comment. The more sophisticated the comment, the more points were awarded. More specifically, up to three points were given for each of the four dimensions. For example, for certainty of knowledge, one point was given for comments that referred to knowledge as certain, two points were given if the participants referred to knowledge as being uncertain, and three points if they considered certainty or uncertainty of knowledge as depending on content and context (for the remaining dimensions and examples see Table 4). Epistemic cognition was operationalized using this coding scheme wherein individuals who earned higher points by using some sort of scientific evidence to justify their comments, for example, were considered more constructivist in their epistemic cognition.

When the comments were too short and could not be evaluated across any of the dimensions due to lack of information, 0 points were assigned. Also, if individuals failed to mention one of the dimensions in their entire comment, 0 points were given for each dimension that was not mentioned. For each individual who provided comments, points for each of their comments were then summed to create a total score. Additionally, individuals' attitude towards vaccination were also considered if they were explicitly stated: individuals were coded as antivaccine, pro-vaccine or having a neutral or balanced view. If the comments were too short to identify their views, they were categorized as no view. A second rater coded $10 \%$ of the comments to establish inter-rater reliability, which was acceptable at $89 \%$. Disagreements were resolved through discussion.

\section{Data Analyses}

To assess the frequency with which each emotion occurred in the comments posted on each website, each coded instance of an emotion was considered as a count of one. Instances were then summed for each emotion to calculate the total frequency. Percentage was then calculated by dividing the number of times a certain emotion appeared by the total number of emotions coded. To assess the quality of arguments used in the websites and across cultures, total scores based on evaluation of sources and processes of justification were calculated for the content of each webpage. Individuals also received a total score based on the quality of their comments as a function of the four epistemic dimensions. For the epistemic quality of each webpage, the credibility of the source, either weak or strong, was counted and frequency percentage was calculated by dividing the number of weak (or strong) claims appearing by the total number of claims coded. For justification, from authority, personal/anecdotal or no support, points were also summed and frequency percentage was calculated. 


\section{Individuals' Emotions}

RESULTS

To address the research question of whether there were any cultural differences in the extent to which individuals expressed negative or positive emotions in response to vaccines, we explored percentage of emotions across the webpages using a chi-square goodness of fit test (conducted only for those with expected values greater than 5\%). The frequency and percentages of social and epistemic emotions per webpage are reported in Tables 5.1 to 5.3. For these analyses, only the pro-attitude and con-attitude websites were taken into consideration. For anger, chi-square analyses revealed a significant difference across cultures, $\chi^{2}=37.47, p<.001$. Specifically, individuals posting on the Japanese websites expressed significantly more anger compared to the North American or Chilean websites. For anxiety, chisquare analyses revealed a significant difference across cultures, $\chi^{2}=9.83, p=.007$. Individuals posting on the Chilean websites expressed significantly more anxiety compared to those in North American or Japan. Finally, for gratitude, chi-square analyses revealed a significant difference across cultures, $\chi^{2}=26.16, p<.001$. Similar to the pattern found for anxiety, more gratitude was expressed on the Chilean websites compared to the North American and Japanese websites.

For the second research question, we probed cultural differences reported above by assessing whether different patterns of emotions arose as a function of attitudes towards vaccinations using a chi-square test for independence. For anger, results revealed a significant relationship between culture and attitude, $\chi^{2}=10.20, p=.006$, wherein more anger was expressed on the Japanese pro-vaccination website (100\%) compared to any other website. Interestingly, for the North American website that included a balanced view, anger (52.11\%) was also the most prominent emotion. In contrast, for the anti-vaccine North American website, anger occurred less frequently (16.67\%), whereas gratitude (30\%) was expressed the most. This trend was similar to the anti-vaccine Japanese website with gratitude (14.81\%), followed by anger and curiosity (11.11\%) as the most frequent emotions.

For gratitude more specifically, results revealed a significant relationship between culture and attitude, $\chi^{2}=28.79, p<.00001$, wherein gratitude was expressed more on the Chilean provaccine website (38\%) compared to the anti-vaccine website $(20.59 \%)$. In contrast, gratitude was expressed more for the anti-vaccine Japanese (14.81\%) and North American (30\%) websites compared to the pro-vaccine websites $(0$, and $6.67 \%$, respectively). With regard to epistemic emotions, curiosity was present across most of the websites except for the provaccine Japanese website. In addition, for all the North American websites, enjoyment was expressed, though to a lesser extent (ranging from 1.41\%-6.67\%). Confusion was mentioned for the website that had balanced view (5.63\%) and for the anti-vaccination webpage (3.33\%).

\section{The Quality of Source and Justification of the Websites' Contents}

To address the third research question of whether there were differences in source and justification strategies used across the different websites as a function of website perspective (pro versus anti-vaccine), the quality of the arguments was considered. As presented in Table 6, North American anti-vaccine websites used invalid and unreliable arguments $100 \%$ of the time, whereas for the pro-vaccine website, of the 34 claims made, strong valid and reliable arguments were used $52.94 \%$ of the time and invalid and unreliable arguments were used $47.06 \%$ of the time. A similar trend was present for the Chilean website; for the anti-vaccine website, invalid and unreliable arguments were used $100 \%$ of the time, and for the pro-vaccine webpage, valid and reliable arguments were used $100 \%$ of the time. In contrast, Japanese antiand pro-vaccine websites showed a different trend. Of the 14 claims made on the anti-vaccine website, $35.71 \%$ were invalid and unreliable arguments, whereas $64.29 \%$ were valid and 
reliable. In contrast, the Japanese pro-vaccine website used invalid and unreliable arguments all of the time (100\%). Finally, of the 107 claims made, the balanced North American website used valid and reliable arguments $84.11 \%$ of the time.

Content analyses revealed that websites that had balanced views relied on evidence from peerreviewed journal articles. Pro-vaccination websites sourced medical experts and justified claims using quotes from experts and journal citations. In contrast, anti-vaccination websites relied on sources from personal experience, and claims were justified using sources such as Wikipedia, news articles or fraudulent research.

For example, in the pro-vaccine North American website, it was mentioned:

"The ability of immunizations to prevent the spread of infection depends on having a certain number of children immunized," says Thomas Saari, M.D., professor of pediatrics at the University of Wisconsin Medical School in Madison. "Scientists refer to this as 'herd immunity.' (from 10 Vaccine Myths-Busted [53])

This was categorized as a valid and reliable claim since the claim was accurate and used testimony from a medical doctor to support the claim.

On the anti-vaccine North American website, links to other resources were provided, but most of them were commercial websites or other unreliable resources such as Wikipedia. For instance, the following claim had a link that led to an unreliable commercial website:

"Vaccinated children are found to be more chronically ill than unvaccinated children with rates for autism, ear infections, ADHD, asthma and allergies as much as 30\% higher than unvaxed children." (From Six Reasons to Say NO to Vaccination [52])

In contrast, the North American balanced view webpage used a good sourcing strategy by supporting claims with peer-reviewed journals, and citing direct quotes from the original journals with links to those sources. For example, one website stated:

In March of 2013, the Journal of Pediatrics published a study titled "Increasing exposure to Antibody-Stimulating Proteins and Polysaccharides (antigens) in Vaccines is Not Associated with Risk of Autism." The study found that vaccines, during the first couple of years of life are not related to the risk of developing an ASD diagnosis. (From The Top Six Reasons Why Parents are Not Vaccinating their Kids [51])

With regard to the justification of the claims made, authoritativeness (i.e., experts) was used for the North American pro-vaccine website (100\%; Table 7), and Chilean pro-vaccine website $(100 \%)$. For example, in the North American pro-vaccine website, doctors with backgrounds in medicine and professors of pediatrics were quoted:

University of Rochester researchers confirmed that when they compared mercury concentrations in the urine, blood and stools of children who got vaccines containing thimerosal with those of kids who received only thimerosal-free vaccines. All the children had mercury levels well below the EPA's most stringent public safety limits. Even if your baby received a vaccine that contained thimerosal, the overwhelming majority of data support a lack of association between the substance and neurological problems, says Margaret Rennels, M.D., the chair of the committee on infectious diseases of the AAP. (From 10 Vaccine Myths-Busted [53])

In the Chilean pro-vaccine website, peer-reviewed journals were often cited and claims from doctors were used for justification. 
For the North American anti-vaccination website, anecdotal evidence was the only form of justification used (100\%). Support for claims was often in the form of their own stories or from their family. For example:

Interestingly, my pediatrician at the time (who was a lifelong friend of our family) had highly recommended that this vaccine be given to my newborn baby at the time. I trusted my instincts and said no to the shot - am I glad I did! My pediatrician (remember, lifelong family friend) subsequently dropped me as a patient. Guess he wasn't such a friend after all! (From Six Reasons to Say NO to Vaccination [52])

No justification was provided on the Japanese pro-vaccine and Chilean anti-vaccine webpages. Authority was used $88.06 \%$ of the time for the balanced North American webpage, with claims justified by vaccine- and medically-related peer-reviewed journal articles:

Regarding the HPV vaccine, a new review was just published in the journal Autoimmunity Reviews titled, "On the relationship between human papilloma virus vaccine and autoimmune disease." They concluded that: "The decision to vaccinate with HPV vaccine is a personal decision, not one that must be made for public health. HPV is not a lethal disease in 95\% of the infections; and the other 5\% are detectable and treatable in the precancerous stage." (From The Top Six Reasons Why Parents are Not Vaccinating their Kids [51])

Similarly, the Japanese anti-vaccine webpage used justification from authority $80 \%$ of the time, using medical expert testimony and deriving data from reliable research, but also used personal justification $20 \%$ of the time.

\section{Individuals' Epistemic Cognition}

To address the question of whether individuals' epistemic cognition differed as a function of website perspective, individual attitude toward vaccinations, and culture, an ANOVA was performed with culture, website perspective and individuals' attitudes as independent variables and scores on each of the dimensions of epistemic cognition as the outcome variable. Levene's test for homogeneity of variance was significant $F=3.618, p<.001$, as such reported results included the adjusted means to correct for this. The means and standard deviations are reported in Table 8.

ANOVAs were conducted on each of the four dimensions independently. For certainty of knowledge, there was a significant main effect of attitude $\left(F(3,68)=23.28, p<.001, \eta^{2}=.44\right)$ and a significant interaction between culture and website $\left(F(2,68)=3.71, p=.03, \eta^{2}=.05\right)$. The simple main effect analysis showed a significant simple main effect of anti-vaccine website and culture as a function of certainty of knowledge $\left(F(2,68)=11.84, p<.001, \eta_{p}{ }^{2}=.258\right)$. More specifically, pairwise comparisons with an LSD correction revealed that the certainty scores were higher in the pro-vaccine North American websites compared to North American antivaccine websites (see Figure 1). The balanced North American website had higher certainty scores than pro-vaccine website or the anti-vaccine North American website. The Japanese anti-vaccine website was found to have higher certainty scores compared to the Japanese provaccine website. Furthermore, when comparing websites within each culture, there was a significant simple main effect of North American websites $\left(F(2,68)=9.30, p<.001, \eta_{p}{ }^{2}=.215\right)$ and Japanese websites $\left(F(1,68)=4.74, p=.033, \eta_{p}^{2}=.065\right)$ with certainty of knowledge as the outcome. More specifically, Chilean pro-vaccine websites had higher certainty scores than North American pro-vaccine websites. Additionally, Chilean anti-vaccine websites had higher certainty scores than North American anti-vaccine websites. Japanese anti-vaccine website had higher certainty scores than the North American anti-vaccine website. 
For simplicity of knowledge, there was a significant main effect of culture $(F(2,67)=9.03, p$ $\left.<.001, \eta^{2}=.15\right)$, and attitude $\left(F(3,67)=4.54, p<.001, \eta^{2}=.11\right)$. There was also a significant interaction between culture and attitude $\left(F(4,67)=3.40, p<.001, \eta^{2}=.11\right)$. Since the interaction was significant, a simple main effect analysis was conducted. There was a significant simple main effect of pro-vaccine attitude and culture as a function of simplicity of knowledge $\left(F(2,67)=9.71, p<.001, \eta_{p}^{2}=.225\right)$. More specifically, pairwise comparisons with an LSD correction revealed that the pro-vaccine attitude holders in North American websites had higher simplicity of knowledge scores compared to those with pro-vaccine attitude holders in Japanese websites (see Figure 2). Pro-vaccine attitude in Chilean websites were found to have higher simplicity scores than Japanese pro-vaccine attitude counterparts. Furthermore, when comparing attitudes within each culture, there was a significant simple main effect of North American $\left(F(3,67)=17.40, p<.001, \eta_{p}^{2}=.438\right)$ and Japanese websites $(F(2,67)=4.64$, $p=.015, \eta_{p}{ }^{2}=.118$ ) and their attitudes on the simplicity of knowledge. Those who did not hold a view in the North American website had significantly lower simplicity of knowledge scores compared to those with a pro-, anti-, or balanced attitude. Simplicity of knowledge was also higher for pro-vaccine attitude holders than their anti-vaccine counterparts in North America. In contrast, pro-vaccine attitude holders on Japanese websites had significantly lower simplicity of knowledge scores than anti-vaccine counterparts. Balanced view holders on Japanese websites, on the other, had significantly higher simplicity of knowledge scores than those with anti-vaccine views, and anti-vaccine attitude holders had higher scores than no view holders.

As for source of knowledge, there was a significant main effect of culture $(F(2,68)=6.75, p$ $\left.<.001, \eta^{2}=.12\right)$, and attitude $\left(F(3,68)=3.21, p=.03, \eta^{2}=.09\right)$ but there was no significant interaction. The post hoc analyses with a LSD correction revealed no significant differences among the three culture but there was a significant difference between no view holders and pro-vaccine $(p<.001)$, anti-vaccine $(p<.001)$ and balanced-view holders $(p<.001)$, in which no view holders held a significantly higher source of knowledge scores than pro-, anti- and balanced view holders. For justification of knowledge, there was a significant main effect of culture $\left(F(2,68)=6.33, p<.001, \eta^{2}=.12\right)$, and attitude $\left(F(3,68)=4.64, p=.01, \eta^{2}=.13\right)$ but there was no interaction. The post hoc analyses with a LSD correction showed significant difference between North America and Chilean culture $(p=.03)$ with Chile holding a significantly higher justification of knowledge scores than North America. There was also a significant difference between no view holders and pro-vaccine $(p<.001)$, anti-vaccine $(p$ $<.001)$, and balanced-view holders $(p<.001)$, in which no view holders held a significantly higher source of knowledge scores than pro-, anti- and balanced view holders. In addition, there was a significant difference among balanced and anti-vaccine view $(p=.04)$ in which those with balanced attitude had a higher justification score than those with anti-vaccine attitudes.

\section{DISCUSSION}

The amount of misinformation widely spread on the Internet requires individuals to think critically about the sources used and justifications provided and necessitates an understanding of the role that emotions play in relation to controversial topics. The current research sought to examine individuals' emotions expressed while responding to content or other individuals' comments on websites about vaccines, and to investigate differences in individuals' epistemic cognition and the quality of epistemic strategies used across various websites. Cross-cultural aspects were taken into consideration, along with website perspective and individuals' attitudes toward vaccinations. 


\section{Individuals' Emotions}

For the first research question, we explored cultural differences in the extent to which individuals express negative and positive emotions in response to controversial arguments. It was found that anger was most prominent in Japanese websites, whereas anxiety and gratitude was most expressed in Chilean websites. For the second research question, differences across cultures were probed as a function of website perspective (pro- or anti-vaccine). Results revealed that anger was most prominent in Japanese pro-vaccination website compared to any other websites. Gratitude was most often expressed in Chilean pro-vaccine website, compared to Chilean anti-vaccine website. However, in Japanese and North American websites, the opposite was true, in which gratitude was expressed most often in North American and Japanese anti-vaccine websites, compared to their pro-vaccine websites. As previous research has shown, anxiety can be more intense for individuals when they hold several misconceptions about a particular topic, like vaccinations, compared to when individuals hold few misconceptions [60]. Therefore, for the Chilean anti-vaccine website, this might imply that individuals accessing the anti-vaccine webpage held stronger misconceptions towards the topic.

Positive emotions are known to promote engagement and conceptual change whereas negative emotions are related to a lack of engagement and resistance to change [13]. Given that gratitude was the most expressed emotion on the anti-vaccine websites for North America and Japan, it may be the case that positive emotions under this condition supported the lack of engagement with the conflicting information, which served to maintain misconceptions. This speaks to the larger issue of misinformation that plagues the Internet - it is likely the case that individuals search for information that further supports their misconceptions or attitudes, fostering positive emotions that increase disengagement with conflicting information, and, subsequently strengthening misconceptions.

Equally troubling was the anger that was expressed on the balanced (North America) and provaccine (Japanese) websites. The experience of anger likely constrained any conceptual change, and may have resulted in the backfire effect given the negative attitudes from those who expressed their anger [26]. In situations that require conceptual change, one key aspect for the change process is to overcome strong emotions but also to change attitudes toward the object of change [35]. In other words, emotion regulation becomes a key aspect but so does attitudinal change. As such, if the goal is to change individuals' misconceptions about vaccinations, it may be necessary to include a positive mood induction element into websites with accurate information in addition to text that attempts to change attitudes towards vaccinations to help foster conceptual change. Future research should explore this possibility as an effective means to foster conceptual and attitudinal change about an emotionally-driven and highly controversial topic.

\section{The Epistemic Quality of Websites' Contents}

For the third research question, we explored differences in quality of arguments as function of attitude and culture across the various websites. It was hypothesized that the anti-vaccine websites would use less valid arguments compared to the pro-vaccine websites. In terms of the cultural aspect, it was hypothesized that reliance on authority would be more prevalent in collectivistic cultures. Analysis of the credibility of sources and justification strategies used across the various websites revealed that the North American balanced view webpage used strong and reliable arguments by citing authority figures to justify the claims made. Moreover, North American pro-vaccine websites primarily used reliable and valid arguments with justification by authority, but did include some unreliable and invalid claims. The Chilean provaccine website presented reliable arguments and used authority to justify claims made. This 
trend was different to that of the Japanese pro-vaccine website, which used unreliable arguments with no justification. The North American anti-vaccine website, on the other, used weak and unreliable arguments most of the time with support provided mostly from anecdotes. This was similar to the Chilean anti-vaccine website, which used weak and invalid arguments most of the time with no form of justification provided. This is in contrast to the Japanese anti-vaccine webpage, which mainly used strong, valid and reliable arguments with justification by authority. Therefore, the hypothesis of whether the quality of argumentation and justification strategies used for anti-vaccine websites would be poor compared to websites that provided pro-vaccine content was supported for North American and Chilean anti-vaccine websites but not for the Japanese anti-vaccine website. Indeed, the use of personal narratives was widepread for the majority of the anti-vaccination websites.

Narrative stories, as used in the North American anti-vaccine webpage, have the potential of appealing to emotion $[12,17]$. However, this may not be true for the Japanese anti-vaccination website, as the source used was mainly derived from authority. Individuals in such a culture are expected to show respect and obedience to elderly and authority figures [43]. Therefore, it might be that differences in source of justification strategies used in North American compared to Japanese webpages were because in North America, emotive appeals might work better whereas in Japan, authority is a more convincing tool used to convey anti-vaccine messages. It is important to note, however, that Yang et al. [32] found that in Taiwan, a collectivistic culture like Japan, individuals' epistemic beliefs mattered in terms of their belief in authority, and that the more individuals examined the content for justification by authority, the less they believed in justification by authority. Future research may need to consider individuals' epistemic beliefs in relation to cultural differences and the effectiveness of emotive versus authorityjustified anti-vaccine messages.

\section{Individuals' Epistemic Cognition and Attitudes}

For the fourth research question, individuals' attitudes towards vaccines, culture and website were examined to explore differences in quality of epistemic cognition. There was no main effect of website found in relation to each of the four aspects of individuals' epistemic cognition. However, there was a significant interaction between culture and website for the certainty of knowledge. More specifically, the arguments individuals used on the North American pro-vaccine website reflected the belief that knowledge certainty depends on context, whereas comments on the anti-vaccine North American website were more reflective of the belief that knowledge is certain, regardless of context. On the other hand, arguments presented by individuals on the Japanese anti-vaccine website were found to be more constructivist, believing knowledge is tentative and evolving compared to those on the provaccine websites. Interestingly, the Japanese anti-vaccine website was found to have comments with higher scores on certainty of knowledge, implying these individuals believed knowledge tentativeness as depending on context, compared to the anti-vaccine North American website counterparts. However, there was no significant difference among the pro-vaccine websites for these two countries. As previous research has shown, those who believe knowledge is actively constructed are known to have better searching strategies while using the Internet and spend more time on reliable resources $[61,31]$.

It may be that in North America, individuals with more constructivist views about vaccine knowledge search for more reliable information, which may lead them more often to provaccine websites given their higher quality in general. In contrast, in Japan, the opposite trend was found, which is counter to previous research. For example, Hofer [45] compared American and Japanese students' epistemic cognition and found that North American students held more constructivist beliefs about knowledge and knowing than their Japanese counterparts, who 
were more likely to view knowledge as simple and certain. In the current research, differences may have occurred due to how the epistemic dimensions were coded. For the certainty of knowledge, highest points were given if they mentioned that certainty or uncertainty depends on context. Japanese individuals are known to endorse harmony with others, and thus have the tendency to keep things ambiguous [39]. Therefore, the wording 'depends on context' used in the coding scheme might have represented the ambiguity that Japanese tend to favor.

For the simplicity of knowledge, results revealed that those with pro-vaccine attitudes had more constructivist views than those holding anti-vaccine views and no views towards vaccines. The simple main effect analysis of culture and attitude on epistemic cognition showed that pro-vaccine attitude holders in North America and Chile used better constructivist arguments than those from Japan, but there were no significant differences among North America and Chile. This was also the case for the simplicity of knowledge, implying that those with pro-vaccine attitudes in North America and Chile saw knowledge as interrelated, whereas in Japan, knowledge was seen as unrelated. Furthermore, in North America, pro-vaccine attitudes were related to higher quality epistemic cognition then anti-vaccine holders. This was the opposite with Japanese individuals, wherein anti-vaccine viewers held more constructivist approaches to knowledge about vaccines than those with pro-vaccines and balanced views.

This result may be related to the fact that arguments used on Japanese websites were in direct contrast to those from their North American and Chilean counterparts. That is, pro-vaccine Japanese websites used weak, invalid arguments with no justifications, whereas the provaccine North American and Chilean websites used strong, valid arguments with justification by authority. In other words, Japanese authors of the websites may not be using constructivist arguments, as measured by the four dimensions of epistemic cognition, in ways similar to those used by North American and Chilean website authors. As Hofer [45] pointed out, nearly all of the frameworks for personal epistemology have been derived from the United States, emphasizing the need to consider whether it is an artifact of Western education or not. Research in argumentative writing has found that Japanese tend to avoid direct confrontation when writing, not stating one's ideas explicitly so the readers inductively draw their own conclusions and thoughts [62]. Japanese students' critical thinking skills are also often criticized for not being fostered in the current educational system in Japan [62], and they generally lack experience in argumentative writing [63]. These differences in language structure, as well as in the education system, might have accounted for differences in epistemic cognition. More cross-cultural research is needed to understand the universality of frameworks of epistemic cognition.

Another reason for the opposite findings in Japanese websites could be related to how their motivation towards the topic affected their processing of information. In other words, motivated reasoning [64], or how individuals' motivations affect their judgements by biasing the information they access and the strategies they use to evaluate the controversial information [13] might have accounted for the results in Japanese anti-vaccine viewers holding more constructivist approaches to knowledge about vaccines. It might be the case that since Japanese individuals with anti-vaccine views have the motivation to withhold their antivaccine belief, they used stronger arguments to convince others that their original belief is true. The current research was not able to measure the motivational aspect of each individual, which should be considered in future research.

Finally, it is important to note that the differences in culture identified here may be due to the websites that were chosen for this research. Since this research only focused on one wepage for each perspective per country (i.e., the most popular), it would be crucial to analyze 
additional webpages, perhaps with different controversial topics, to observe if the cultural differences found in this research are generalizable.

\section{CONCLUSION}

Access to information on the Internet is limitless. In a world where Web 2.0 is becoming more common, it is impossible to control the type of information that individuals can access. Individuals must be taught to judge the veracity of information and assess the source quality to ensure misconceptions are not developed or strengthened. Given that individuals often rely on the Internet to make health-related decisions, this is of critical importance. Results of this current research provide insight into the importance of debate perspective in triggering specific emotions and shed light into possible cultural differences in emotional expression, arguments used on the websites, and the attitudes individuals have about controversial health issues.

\section{References}

Kata, A. (2012). Anti-vaccine activists, Web 2.0, and the postmodern paradigm: An overview of tactics and tropes used online by the anti-vaccination movement. Vaccine, 30(25), 3778-3789. doi: 10.1016/j.vaccine.2011.11.112

Kortum, P., Edwards, C., \& Richards-Kortum, R. (2008). The impact of inaccurate Internet health information in a secondary school learning environment. Journal of Medical Internet Research, 10(2), 1-11. doi: 10.2196/jmir.986

Barzilai, S., \& Zohar, A. (2014). Reconsidering personal epistemology as metacognition: A multifaceted approach to the analysis of epistemic thinking. Educational Psychologist, 49(1), 13-35. doi:10.1080/00461520.2013.863265

Pekrun, R., Goetz, T., Daniels, L. M., Stupnisky, R. H., \& Perry, R. P. (2010). Boredom in achievement settings: Exploring control-value antecedents and performance outcomes of a neglected emotion. Journal of Educational Psychology, 102, 531-549.

Pekrun, R., Goetz, T., Frenzel, A. C., Barchfeld, P., \& Perry, R.P. (2011). Measuring emotions in students' learning and performance : The Achievement Emotions Questionnaire (AEQ), 36.

Pekrun, R., \& Stephens, E. J. (2012). Academic emotions. In K. R. Harris (Ed.), APA educational psychology handbook, Vol. 2: Individual differences and cultural and contextual factors (pp. 3-31). Washington, DC: American Psychological Association.

Hofer, B. K., \& Pintrich, P. R. (1997). The development of epistemological theories: Beliefs about knowledge and knowing and their relation to learning. Review of Educational Research, 67(1), 88-140. doi: 10.3102/00346543067001088

Hofer, B.K. (2008). Personal epistemology and culture. In M.S., Khine (Ed.), Knowing, knowledge and beliefs: epistemological studies across diverse cultures (pp. 3-22). Dordrecht, Netherlands: Springer.

Strømsø, H. I., \& Kammerer, Y. (2016). Epistemic cognition and reading for understanding in the internet age. Handbook of epistemic cognition (pp 230-246). New York, NY: Taylor \& Francis.

Pekrun, R. (2006). The control-value theory of achievement emotions: Assumptions, corollaries, and implications for educational research and practice. Educational Psychology Review, 18, 315-341.

Pekrun, R., \& Perry, R. P. (2014). Control value theory of achievement emotions. In R. Pekrun \& L. LinnenbrinkGarcia (Eds.), International handbook of emotions in education (pp. 120-141). New York,NY: Taylor \& Francis.

Betsch, C., Brewer, N. T., Brocard, P., Davies, P., Gaissmaier, W., Haase, N., ... Stryk, M. (2012). Opportunities and challenges of Web 2.0 for vaccination decisions. Vaccine, 30(25), 3727-3733. doi: 10.1016/j.vaccine.2012.02.025

Sinatra, G.M., Kienhues, D., \& Hofer, B.K. (2014a). Addressing challenges to public understanding of science: Epistemic cognition, motivated reasoning, and conceptual change. Educational Psychologist, 49(2), $123-138$. doi:10.1080/00461520.2014.916216.

Wakefield, A., Murch, S., Anthony, A., Linnell, J., Casson, D., Malik, M., Berelowitz, M., Dhillon, A., Thomson, M., Harvey, P., Valentine, A., Davies, S. \& Walker-Smith, J. (1998). Ileallymphoid-nodular hyperplasia, non-specific colitis, and pervasive developmental disorder in children. Lancet, 351, 637-641. doi: 10.1016/S0140$\underline{6736(97) 11096-0}$ 
Kata, A. (2010). A postmodern Pandora's box: Anti-vaccination misinformation on the Internet. Vaccine, 28(7), 1709-1716. doi: 10.1016/j.vaccine.2009.12.022

Betsch, C., Renkewitz, F., Betsch, T., \& Ulshöfer, C. (2010). The influence of vaccine-critical websites on perceiving vaccination risks. Journal of Health Psychology, 15, 446-455. doi: 10.1177/1359105309353647

Betsch C, Ulshöfer C, Renkewitz F, \& Betsch T. (2011). The influence of narrative vs. statistical information on perceiving vaccination risks. Medical Decision Making, 31(5),742-53.

Kleinginna, P. R., \& Kleinginna, A. M. (1981). A categorized list of emotion definitions, with suggestions for a consensual definition, Motivation and Emotion, 5(3), pp 263-291. doi:10.1007/BF00993889

Scherer, K. R. (2000). Psychological models of emotion. The Neuropsychology of Emotion, 6, 137-162.

Pekrun, R., \& Linnenbrink-Garcia, L. (2014). International handbook of emotions in education. New York, NY: Routledge.

Muis, R. R., Chevrier, M., \& Singh, C. (2018). The role of epistemic emotions in personal epistemology and selfregulated learning. Educational Psychologist. doi.org/10.1080/00461520.2017.1421465

Sinatra, G.M., Broughton, S.H., \& Lombardi, D. (2014b). Emotions in science education. In R. Pekrun \& L. Linnenbrink-Garcia (Eds.), International handbook of emotions in education (pp. 415-436). New York, NY: Taylor \& Francis.

Mason, L., \& Boldrin, A. (2008). Epistemic metacognition in the context of information searching on the Web. In M.S., Khine (Ed.), Knowing, knowledge and beliefs: epistemological studies across diverse cultures (pp. 377-404). Dordrecht, Netherlands: Springer.

Linnenbrink-Garcia, L., Rogat, T. K., \& Koskey, K. L. K. (2011). Affect and engagement during small group instruction. Contemporary Educational Psychology, 36, 13-24.

D’Mello, S. \& Graesser, A. (2012). Dynamic affective states during complex learning. Learning and Instruction, 22, 145-157.

Trevors, G., Muis, K. R., Pekrun, R., Sinatra, G., \& Winne, P. H. (2016). Identity and epistemic emotions during knowledge revision : A potential account for the backfire effect. Discourse Processes, 53, 339-370. doi: 10.1080/0163853X.2015.1136507

Nyhan, B., Reifler, J., Richey, S., \& Freed, G. L. (2014). Effective messages in vaccine promotion: A randomized trial. Pediatrics, 133(4), e835-e842. doi: 10.1542/peds.2013-2365

Hofer, B. K., \& Bendixen, L. D. (2012). Personal epistemology: Theory, research, and future directions. In K. R. Harris, S. Graham, T. Urdan, C. B. McCormick, G. M. Sinatra, \& J. Sweller (Eds.), APA educational psychology handbook, Vol. 1: Theories, constructs, and critical issues (pp. 227-256). Washington, DC: American Psychological Association.

Mason, L., Ariasi, N., \& Boldrin, A. (2011). Epistemic beliefs in action: Spontaneous reflections about knowledge and knowing during online information searching and their influence on learning. Learning and Instruction, 21(1), 137-151. doi: 10.1016/j.learninstruc.2010.01.001

Mason, L., Boldrin, A., \& Ariasi, N. (2010). Searching the Web to learn about a controversial topic: Are students epistemically active? Instructional Science, 38(6), 607-633. doi: 10.1007/s11251-008-9089-y

Mason, L., Pluchino, P., \& Ariasi, N. (2014). Reading information about a scientific phenomenon on webpages varying for reliability: An eye-movement analysis. Educational Technology Research and Development, 62(6), 663685. doi:10.1007/s11423-014-9356-3

Yang, F.-Y., Chen, Y. H. \& Tsai, M.-J. (2013). How university students evaluate online information about a socioscientific issue and the relationship with their epistemic beliefs. Educational Technology \& Society, 16(3), 385399.

Heddy, B. C., Danielson, R. W., Sinatra, G. M., \& Graham, J. (2017). Modifying Knowledge, Emotions, and Attitudes Regarding Genetically Modified Foods. The Journal of Experimental Education, 85(3), 513-533. doi: 10.1080/00220973.2016.1260523

Southerland, S.A., Sinatra, G.M. \& Matthews, M.R. (2001). Belief, knowledge, and science education. Educational Psychology Review, 13, 325-351. doi:10.1023/A:1011913813847

Sinatra, G.M., \& Seyranian, V. (2016). Warm change about hot topics: The role of motivation and emotion in attitude and conceptual change about controversial science topics. In L. Corno \& E. Anderman (Eds.), $A P A$ handbook of educational psychology (3 ${ }^{\text {rd }}$ ed., pp. 245-256). New York, NY: Routledge. 
Eagly, A.H., \& Chaiken, S. (1993). The psychology of attitudes. Fort Worth, TX: Harcourt Brace.

Bråten, I. (2008). Personal epistemology, understanding of multiple texts, and learning within internet technologies. In M.S., Khine (Ed.), Knowing, knowledge and beliefs: Epistemological studies across diverse cultures (pp. 351-376). Dordrecht, Netherlands: Springer.

Tsai, J. L., Levenson, R. W., \& McCoy, K. (2006). Cultural and temperamental variation in emotional response. Emotion, 6(3), 484-497. doi: 10.1037/1528-3542.6.3.484

Markus, H. R., \& Kitayama, S. (1991). Culture and the self: Implications for cognition, emotion, and motivation. Psychological review, 98(2), 224.

Frenzel, A. C., Thrash, T. M., Pekrun, R., \& Goetz, T. (2007). Achievement emotions in Germany and China: A crosscultural validation of the Academic Emotions Questionnaire--Mathematics. Journal of Cross-Cultural Psychology, 38(3), 302-309. doi: 10.1177/0022022107300276

DeCuir-Gunby, J.T., \& Williams-Johnson, M.R. (2014). The influence of culture on emotions: Implications for education. In R. Pekrun \& L. Linnenbrink-Garcia (Eds.), International handbook of emotions in education (pp. 539557). New York, NY: Taylor \& Francis.

Muis, K. R., Bendixen, L. D., \& Haerle, F. C. (2006). Domain-generality and domain-specificity in personal epistemology research: Philosophical and empirical reflections in the development of a theoretical framework. Educational Psychology Review, 18(1), 3-54. doi: 10.1007/s10648-006-9003-6

Chan, K., \& Elliott, R. G. (2004). Epistemological beliefs across cultures: Critique and analysis of beliefs structure studies. Educational Psychology, 24(2), 123-142. doi: 10.1080/0144341032000160100

Hofer, B. K. (2001). Personal epistemology research : Implications for learning and teaching. Journal of Educational Psychology, 13(4), 353-383. doi: 10.1023/A:1011965830686

Hofer, B.K. (2010). Personal epistemology, learning, and cultural context: Japan and the United States. In M. Baxter Magolda, E. G. Credmer, \& P. S. Meszaros (Eds.), Development and assessment of self-authorship: Exploring the concept across cultures (pp. 133-148). Sterling, VA: Stylus.

Strømsø, H. I., Bråten, I., Anmarkrud, Ø., \& Ferguson, L. E. (2016). Beliefs about justification for knowing when ethnic majority and ethnic minority students read multiple conflicting documents. Educational Psychology, 36, 638-657.

Ekman, P. (1999). Facial expressions. In T. Dalgleish, \& T. Power (Eds.), Handbook of cognition and emotion (pp. 301-320). Chichester, UK: Wiley

Triandis, H. C. (2001). Individualism-Collectivism and Personality. Journal of Personality, 696.

Muis, K.R., \& Sinatra, G.M. (2008). University cultures and epistemic beliefs: Examining differences between two academic environments. In M.S., Khine (Ed.), Knowing, knowledge and beliefs: epistemological studies across diverse cultures (pp. 137-150). Dordrecht, Netherlands: Springer.

Wolfe, R. M., \& Sharp, L. K. (2005). Vaccination or immunization? The impact of search terms on the internet. Journal of Health Communication, 10(6), 537-51. doi: 10.1080/10810730500228847

The Top 6 Reasons Why Parents Are Choosing Not To Vaccinate Their Kids. (2015, February 15). Retrieved March 07, 2016, from http://www.collective-evolution.com/2015/02/15/the-top-6-reasons-why-parents-are-choosingnot-to-vaccinate-their-kids/

Six Reasons to Say NO to Vaccination. (2015, January 01). Retrieved March 07, 2016, from

http://www.thehealthyhomeeconomist.com/six-reasons-to-say-no-to-vaccination/

Ten Vaccine Myths-Busted. (2014, July 11). Retrieved March 07, 2016, from

http://www.parenting.com/article/10-vaccine-myths---busted

Sekai no uragawa news [News from the other side of the world]. (2014, April 26). Retrieved March 07, 2016, from http://ameblo.jp/wake-up-japan/entry-11834538611.html

Are you against or pro-vaccines? (2014, December 11). Retrieved March 07, 2016, from http://www.scienceplus2ch.com/archives/4925948.html

Vacunas Infantiles: Peligrosas e Innecesarias. [Infant vaccines: Dangerous and unnecessary]. (2011, October 26). Retrieved March 07, 2016, from https://detenganlavacuna.wordpress.com/2011/10/26/vacunas-infantiles/ 
Paremos la locura anti-vacunación infantil. [Let's stop the insanity of infant anti-vaccination]. (2013, April 30). Retrieved March 07, 2016, from http://www.elquintopoder.cl/ciencia/paremos-la-locura-anti-vacunacioninfantil/

Pekrun, R., Meier, E., Muis, K. R., \& Sinatra, G. M. (2017). Measuring emotions during epistemic activities: The Epistemically-Related Emotions Scales (EES). Cognition and Emotion.

Chinn, C. A., Buckland, L. A., \& Samarapungavan, A. L. A. (2011). Expanding the dimensions of epistemic cognition: Arguments from philosophy and psychology. Educational Psychologist, 46, 141-167.

Broughton, S.H., Pekrun, R., \& Sinatra, G.M. (2012). Climate change, genetically modified foods, airport body scanners: Investigating students' emotions related to science topics. Paper presented at the American Educational Research Association, Vancouver, CA.

Tu, Y. W., Shih, M., \& Tsai, C. C. (2008). Eighth graders' web searching strategies and outcomes: The role of task types, web experiences and epistemological beliefs. Computers and Education, 51(3), 1142-1153. doi: 10.1016/j.compedu.2007.11.003

McKinley, J. (2013). Displaying critical thinking in EFL academic writing: A discussion of Japanese to English contrastive rhetoric. RELC Journal, 44(2), 195-208.

Hirose, K. (2003). Comparing L1 and L2 organizational patterns in the argumentative writing of Japanese EFL students. Journal of second language writing, 12(2), 181-209.

Kunda, Z. (1990). The case for motivated reasoning. Psychological Bulletin, 108, 480-498. doi: 10.1037/00332909.108.3.480 
Table 1

Definitions of Social Emotions and Examples

\begin{tabular}{|c|c|c|}
\hline Social Emotion & Definition & Examples \\
\hline Anger & $\begin{array}{l}\text { Anger to others' thoughts, anger directed to } \\
\text { other people }\end{array}$ & $\begin{array}{l}\text { "it sickens me", "stupid ignorant fools", } \\
\text { "stupid is as stupid does", "this is } \\
\text { absurd"” Educate yourself" }\end{array}$ \\
\hline Sadness & $\begin{array}{l}\text { Sad feelings to other people, other people's } \\
\text { thoughts }\end{array}$ & $\begin{array}{l}\text { "sad that....","it saddens me"," it's } \\
\text { really sad that..." }\end{array}$ \\
\hline Worry & $\begin{array}{l}\text { Feeling worried for oneself as a result of others' } \\
\text { behavior, reaction }\end{array}$ & "Tell me this isn't all related..." \\
\hline Anxiety & $\begin{array}{l}\text { Anxiety about information provided by others or } \\
\text { anxiety about group behavior, or about group } \\
\text { performance. }\end{array}$ & "Does alarm me”, 'I'm so nervous" \\
\hline Gratitude & $\begin{array}{l}\text { Feelings of appreciation for other people's } \\
\text { behavior and/or action. }\end{array}$ & $\begin{array}{l}\text { "I appreciate...", "thanks for the } \\
\text { article", "I'm glad", "thank you so much } \\
\text { for saying this..." }\end{array}$ \\
\hline Fear & $\begin{array}{l}\text { Feeling fear as a result of information/action } \\
\text { from others }\end{array}$ & $\begin{array}{l}\text { "The part that scares me...", "It scares } \\
\text { me", "it's scary..." }\end{array}$ \\
\hline Doubt & $\begin{array}{l}\text { Feeling doubt as a result of information/action } \\
\text { of others }\end{array}$ & $\begin{array}{l}\text { "I doubt the majority of Anti-Vaxx'rs } \\
\text { are against vaccination", "In my heart I } \\
\text { doubt vaccinating" }\end{array}$ \\
\hline Hope & $\begin{array}{l}\text { To want something to happen or to be true and } \\
\text { think it could happen or become true }\end{array}$ & $\begin{array}{l}\text { "I think it's fair to say that we are all } \\
\text { looking forward" }\end{array}$ \\
\hline \multirow[t]{2}{*}{ Encouragement } & Giving others support & $\begin{array}{l}\text { "Please keep talking because you are } \\
\text { so unselfish by doing this and you are } \\
\text { helping others" }\end{array}$ \\
\hline & & $\begin{array}{l}\text { "...give you the courage to continue } \\
\text { telling the TRUTH that many are not } \\
\text { hearing" }\end{array}$ \\
\hline Regret & $\begin{array}{l}\text { Disappointment to things that has already } \\
\text { happened }\end{array}$ & "I would never have done it" \\
\hline Shock & $\begin{array}{l}\text { Feeling shock as a result of information/action } \\
\text { of others }\end{array}$ & $\begin{array}{l}\text { "horribly shocked to see that SEVERAL } \\
\text { DOZENS of girls vaccinated against } \\
\text { HPV fainted" }\end{array}$ \\
\hline Disgust & $\begin{array}{l}\text { Feeling profound disapproval as a result of } \\
\text { information/action of others }\end{array}$ & $\begin{array}{l}\text { "I have no respect for people who use } \\
\text { science as club" }\end{array}$ \\
\hline Annoyed & $\begin{array}{l}\text { Feeling irritated as a result of } \\
\text { information/action of others }\end{array}$ & "one point that really bugs me" \\
\hline Painful & $\begin{array}{l}\text { Feeling pain as a result of information/action of } \\
\text { others }\end{array}$ & $\begin{array}{l}\text { "I'm in deep pain for the choice I } \\
\text { made" }\end{array}$ \\
\hline
\end{tabular}


Table 2

Definitions of Epistemic Emotions and Examples

\begin{tabular}{|c|c|c|}
\hline $\begin{array}{l}\text { Epistemic } \\
\text { Emotion }\end{array}$ & Definition & Examples \\
\hline Surprise & Surprised about incoming information. & $\begin{array}{l}\text { "Big surprise" “Wow! I didn't know } \\
\text { that." “Hm, I didn't expect that." }\end{array}$ \\
\hline Confusion & Confused about the information given. & $\begin{array}{l}\text { "I don't get it." "I don't understand." } \\
\text { I'm confused." "I'm not sure why", "I } \\
\text { really don't know what to think about } \\
\text { this" }\end{array}$ \\
\hline Curiosity & Curious to learn or know more about something. & $\begin{array}{l}\text { "I wonder..." "I'm interested in } \\
\text { knowing..." "maybe..." “I would be } \\
\text { curious", "Where did you get the } \\
\text { information?" }\end{array}$ \\
\hline Enjoyment & Enjoying success in understanding/learning. & "It brings me joy knowing" \\
\hline Frustration & Frustrated about not understanding or learning. & $\begin{array}{l}\text { "Ugh, I don't get this!" "Well, this just } \\
\text { makes me angry." }\end{array}$ \\
\hline
\end{tabular}

Table 3

Definition of Epistemic Cognition of the Webpage and Examples

\begin{tabular}{|c|c|c|}
\hline $\begin{array}{c}\text { Credibility and Justification } \\
\text { of Support }\end{array}$ & Definition (Source used) & Examples \\
\hline $\begin{array}{l}\text { Weak/Invalid and } \\
\text { Unreliable }\end{array}$ & $\begin{array}{l}\text { Wikipedia } \\
\text { Magazines } \\
\text { Anecdotal } \\
\text { No support }\end{array}$ & $\begin{array}{l}\text { "My own Father (retired) is a MD as is my } \\
\text { brother and my cousin (who was a } \\
\text { pediatrician, now deceased). "My } \\
\text { husband's mother is a nurse." }\end{array}$ \\
\hline Strong/Valid and Reliable & $\begin{array}{l}\text { Published articles } \\
\text { Expert source } \\
\text { Scientific support }\end{array}$ & $\begin{array}{l}\text { "It's the natural evolution of a vaccine } \\
\text { program," says Paul Offit, M.D., chief of } \\
\text { infectious diseases and director of the } \\
\text { Vaccine Education Center at the } \\
\text { Children's Hospital of Philadelphia. " }\end{array}$ \\
\hline
\end{tabular}


Table 4

Coding Scheme for Epistemic Cognition - Webpage Comments

\begin{tabular}{|c|c|c|}
\hline $\begin{array}{c}\text { Four } \\
\text { Dimensions }\end{array}$ & Definition & Examples \\
\hline $\begin{array}{l}\text { Simplicity of } \\
\text { Knowledge }\end{array}$ & $\begin{array}{l}1 \text { pt.: knowledge is certain } \\
2 \text { pts.: uncertain } \\
3 \text { pts: certainty-uncertainty } \\
\text { depends on content } \\
1 \text { pt.: collection of multiple } \\
\text { information, one source } \\
2 \text { pts.: comparison of multiple } \\
\text { information } \\
3 \text { pts: shared scientific answer }\end{array}$ & $\begin{array}{l}\text { Earned three points on each aspect: The man who } \\
\text { started this craze has been disbarred. He published a } \\
\text { study based on EIGHT subjects, come to find out he } \\
\text { wanted the current MMR vaccine taken off the market } \\
\text { because he had come up with a new vaccine for MMR, } \\
\text { and wanted his to be used instead. Conflict of interest? } \\
\text { duh. (From The Top Six Reasons Why Parents are Not } \\
\text { Vaccinating their Kids) }\end{array}$ \\
\hline $\begin{array}{l}\text { Source of } \\
\text { Knowledge }\end{array}$ & $\begin{array}{l}1 \text { pt.: popularity of source, } \\
\text { anecdotal } \\
2 \text { pts.: authoritativeness } \\
\text { /expertise of source }\end{array}$ & $\begin{array}{l}\text { Earned one point on each aspect: } 5 \text { years ago, I took } \\
\text { all the required shots to work in the hospital, } \\
\text { Meningitis, Hepatitis A and B, Flu, MMR... Must say } \\
\text { these vaccinations broke my strength and } \\
\text { performance down by at least } 25 \% \text {. }\end{array}$ \\
\hline $\begin{array}{l}\text { Justification } \\
\text { for Knowing }\end{array}$ & $\begin{array}{l}1 \text { pt.: knowledge cannot be } \\
\text { evaluated } \\
2 \text { pts.: agreement / disagreement } \\
\text { with one's knowledge } \\
3 \text { pts: scientific evidence }\end{array}$ & $\begin{array}{l}\text { old and it have been } 5 \text { years since I took them and } \\
\text { could feel my body progressively physically } \\
\text { weakening for the duration. I no longer work at the } \\
\text { hospital, and if I knew I was trading off my health for a } \\
\text { job after school, I would never have done it. (From Six } \\
\text { Reasons to Say NO to Vaccination) }\end{array}$ \\
\hline
\end{tabular}


Table 5.1

Frequency and Percentage of each Emotions for North American Websites

\begin{tabular}{|c|c|c|c|c|c|c|c|c|c|}
\hline & \multicolumn{3}{|c|}{ Balanced } & \multicolumn{3}{|c|}{ Anti-Vaccines } & \multicolumn{3}{|c|}{ Pro-Vaccines } \\
\hline & $f$ & $\begin{array}{c}\% \text { per } \\
\text { Segments }\end{array}$ & $\begin{array}{c}\% \text { per } \\
\text { Emotions } \\
\end{array}$ & $f$ & $\begin{array}{c}\% \text { per } \\
\text { Segments }\end{array}$ & $\begin{array}{c}\% \text { per } \\
\text { Emotions } \\
\end{array}$ & $f$ & $\begin{array}{c}\% \text { per } \\
\text { Segments }\end{array}$ & $\begin{array}{c}\text { \% per } \\
\text { Emotions }\end{array}$ \\
\hline \multicolumn{10}{|l|}{ Social Emotions } \\
\hline Anger & 37 & 5.73 & 52.11 & 5 & 1.84 & 16.67 & 15 & 4.18 & 50.00 \\
\hline Sadness & 4 & 0.62 & 5.63 & 3 & 1.10 & 10.00 & 4 & 1.11 & 13.33 \\
\hline Worry & 2 & 0.31 & 2.82 & 0 & 0.00 & 0.00 & 0 & 0.00 & 0.00 \\
\hline Anxiety & 1 & 0.15 & 1.41 & 5 & 1.84 & 16.67 & 0 & 0.00 & 0.00 \\
\hline Gratitude & 10 & 1.55 & 14.08 & 9 & 3.31 & 30.00 & 2 & 0.56 & 6.67 \\
\hline Fear & 1 & 0.15 & 1.41 & 1 & 0.37 & 3.33 & 1 & 0.28 & 3.33 \\
\hline Doubt & 0 & 0.00 & 0.00 & 1 & 0.37 & 3.33 & 1 & 0.28 & 3.33 \\
\hline Hope & 1 & 0.15 & 1.41 & 0 & 0.00 & 0.00 & 0 & 0.00 & 0.00 \\
\hline Encouragement & 2 & 0.31 & 2.82 & 1 & 0.37 & 3.33 & 0 & 0.00 & 0.00 \\
\hline Regret & 0 & 0.00 & 0.00 & 1 & 0.37 & 3.33 & 0 & 0.00 & 0.00 \\
\hline Shock & 0 & 0.00 & 0.00 & 1 & 0.37 & 3.33 & 1 & 0.28 & 3.33 \\
\hline Disgust & 1 & 0.15 & 1.41 & 0 & 0.00 & 0.00 & 0 & 0.00 & 0.00 \\
\hline Annoyed & 1 & 0.15 & 1.41 & 0 & 0.00 & 0.00 & 0 & 0.00 & 0.00 \\
\hline Painful & 0 & 0.00 & 0.00 & 0 & 0.00 & 0.00 & 0 & 0.00 & 0.00 \\
\hline \multicolumn{10}{|c|}{ Epistemic Emotions } \\
\hline Surprise & 2 & 0.31 & 2.82 & 0 & 0.00 & 0.00 & 0 & 0.00 & 0.00 \\
\hline Confusion & 4 & 0.62 & 5.63 & 1 & 0.37 & 3.33 & 0 & 0.00 & 0.00 \\
\hline Curiosity & 4 & 0.62 & 5.63 & 1 & 0.37 & 3.33 & 4 & 1.11 & 13.33 \\
\hline Enjoyment & 1 & 0.15 & 1.41 & 1 & 0.37 & 3.33 & 2 & 0.56 & 6.67 \\
\hline$n$ Emotions & 71 & & & 30 & & & 30 & & \\
\hline $\begin{array}{l}n \text { Segmented } \\
\text { Sections }\end{array}$ & 646 & & & 272 & & & 359 & & \\
\hline
\end{tabular}


Table 5.2

Frequency and Percentage of each Emotions for Japanese Websites

\begin{tabular}{|c|c|c|c|c|c|c|}
\hline & \multicolumn{3}{|c|}{ Anti-Vaccines } & \multicolumn{3}{|c|}{ Pro-Vaccines } \\
\hline & $f$ & $\begin{array}{c}\% \text { per } \\
\text { Segments }\end{array}$ & $\begin{array}{c}\% \text { per } \\
\text { Emotions }\end{array}$ & $f$ & $\begin{array}{c}\% \text { per } \\
\text { Segments }\end{array}$ & $\begin{array}{c}\% \text { per } \\
\text { Emotions }\end{array}$ \\
\hline \multicolumn{7}{|l|}{ Social Emotions } \\
\hline Anger & 3 & 1.39 & 11.11 & 5.00 & 5.26 & 100.00 \\
\hline Sadness & 1 & 0.46 & 3.70 & 0.00 & 0.00 & 0.00 \\
\hline Worry & 1 & 0.46 & 3.70 & 0.00 & 0.00 & 0.00 \\
\hline Anxiety & 2 & 0.93 & 7.41 & 0.00 & 0.00 & 0.00 \\
\hline Gratitude & 4 & 1.85 & 14.81 & 0.00 & 0.00 & 0.00 \\
\hline Fear & 2 & 0.93 & 7.41 & 0.00 & 0.00 & 0.00 \\
\hline Doubt & 1 & 0.46 & 3.70 & 0.00 & 0.00 & 0.00 \\
\hline Hope & 1 & 0.46 & 3.70 & 0.00 & 0.00 & 0.00 \\
\hline Encouragement & 3 & 1.39 & 11.11 & 0.00 & 0.00 & 0.00 \\
\hline Regret & 1 & 0.46 & 3.70 & 0.00 & 0.00 & 0.00 \\
\hline Shock & 0 & 0.00 & 0.00 & 0.00 & 0.00 & 0.00 \\
\hline Disgust & 0 & 0.00 & 0.00 & 0.00 & 0.00 & 0.00 \\
\hline Annoyed & 0 & 0.00 & 0.00 & 0.00 & 0.00 & 0.00 \\
\hline Painful & 2 & 0.93 & 7.41 & 0.00 & 0.00 & 0.00 \\
\hline \multicolumn{7}{|l|}{ Epistemic Emotions } \\
\hline Surprise & 2 & 0.93 & 7.41 & 0.00 & 0.00 & 0.00 \\
\hline Confusion & 0 & 0.00 & 0.00 & 0.00 & 0.00 & 0.00 \\
\hline Curiosity & 3 & 1.39 & 11.11 & 0.00 & 0.00 & 0.00 \\
\hline Enjoyment & 1 & 0.46 & 3.70 & 0.00 & 0.00 & 0.00 \\
\hline$n$ Emotions & 27 & & & 5 & & \\
\hline$n$ Segmented Sections & 216 & & & 95 & & \\
\hline
\end{tabular}


Table 5.3

Frequency and Percentage of each Emotions for Chilean Websites

\begin{tabular}{|c|c|c|c|c|c|c|}
\hline \multirow[b]{3}{*}{ Social Emotions } & \multicolumn{3}{|c|}{ Anti-Vaccines } & \multicolumn{3}{|c|}{ Pro-Vaccines } \\
\hline & \multirow[t]{2}{*}{$f$} & \multirow[t]{2}{*}{$\begin{array}{c}\% \text { per } \\
\text { Segments }\end{array}$} & \multirow[t]{2}{*}{$\begin{array}{c}\% \text { per } \\
\text { Emotions }\end{array}$} & \multirow[t]{2}{*}{$f$} & \multirow[t]{2}{*}{$\begin{array}{c}\% \text { per } \\
\text { Segments }\end{array}$} & \multirow[t]{2}{*}{$\begin{array}{c}\% \text { per } \\
\text { Emotions }\end{array}$} \\
\hline & & & & & & \\
\hline Anger & 4 & 1.00 & 11.76 & 4 & 0.81 & 30.77 \\
\hline Sadness & 2 & 0.50 & 5.88 & 2 & 0.40 & 15.38 \\
\hline Worry & 0 & 0.00 & 0.00 & 0 & 0.00 & 0.00 \\
\hline Anxiety & 9 & 2.25 & 26.47 & 0 & 0.00 & 0.00 \\
\hline Gratitude & 7 & 1.75 & 20.59 & 5 & 1.01 & 38.46 \\
\hline Fear & 0 & 0.00 & 0.00 & 0 & 0.00 & 0.00 \\
\hline Doubt & 4 & 1.00 & 11.76 & 0 & 0.00 & 0.00 \\
\hline Hope & 0 & 0.00 & 0.00 & 0 & 0.00 & 0.00 \\
\hline Encouragement & 3 & 0.75 & 8.82 & 0 & 0.00 & 0.00 \\
\hline Regret & 1 & 0.25 & 2.94 & 0 & 0.00 & 0.00 \\
\hline Shock & 0 & 0.00 & 0.00 & 0 & 0.00 & 0.00 \\
\hline Disgust & 0 & 0.00 & 0.00 & 0 & 0.00 & 0.00 \\
\hline Annoyed & 0 & 0.00 & 0.00 & 0 & 0.00 & 0.00 \\
\hline Painful & 0 & 0.00 & 0.00 & 1 & 0.20 & 7.69 \\
\hline \multicolumn{7}{|l|}{ Epistemic Emotions } \\
\hline Surprise & 0 & 0.00 & 0.00 & 0 & 0.00 & 0.00 \\
\hline Confusion & 0 & 0.00 & 0.00 & 0 & 0.00 & 0.00 \\
\hline Curiosity & 4 & 1.00 & 11.76 & 1 & 0.20 & 7.69 \\
\hline Enjoyment & 0 & 0.00 & 0.00 & 0 & 0.00 & 0.00 \\
\hline$n$ of Emotions & 34 & & & 13 & & \\
\hline$n$ Segmented Sections & 400 & & & 495 & & \\
\hline
\end{tabular}


Table 6

Frequency and Percentage of the Credibility of Source per Website

\begin{tabular}{|c|c|c|c|c|c|c|c|c|c|}
\hline \multirow[b]{3}{*}{$\begin{array}{l}\text { North } \\
\text { America }\end{array}$} & \multicolumn{3}{|c|}{ Balanced } & \multicolumn{3}{|c|}{ Anti-Vaccines } & \multicolumn{3}{|c|}{ Pro-Vaccines } \\
\hline & $f$ & $\begin{array}{c}\% \text { per } \\
\text { segments }\end{array}$ & $\begin{array}{l}\% \text { per } \\
\text { claims }\end{array}$ & $f$ & $\begin{array}{c}\% \text { per } \\
\text { segments }\end{array}$ & $\begin{array}{l}\% \text { per } \\
\text { claims }\end{array}$ & $f$ & $\begin{array}{c}\% \text { per } \\
\text { segments }\end{array}$ & $\begin{array}{l}\% \text { per } \\
\text { claims }\end{array}$ \\
\hline & & & & & & & & & \\
\hline $\begin{array}{l}\text { Invalid and } \\
\text { Unreliable }\end{array}$ & 17 & 12.14 & 15.89 & 38 & 62.30 & 100 & 16 & 41.03 & 47.06 \\
\hline $\begin{array}{l}\text { Valid and } \\
\text { Reliable }\end{array}$ & 90 & 64.29 & 84.11 & 0 & 0.00 & 0.00 & 18 & 46.15 & 52.94 \\
\hline$n$ of Segments & 140 & & & 61 & & & 39 & & \\
\hline$n$ of Claims & 107 & & & 38 & & & 34 & & \\
\hline \multicolumn{10}{|l|}{ Japan } \\
\hline $\begin{array}{l}\text { Invalid and } \\
\text { Unreliable }\end{array}$ & & & & 5 & 27.78 & 35.71 & 4 & 40.00 & 100 \\
\hline $\begin{array}{l}\text { Valid and } \\
\text { Reliable }\end{array}$ & & & & 9 & 50.00 & 64.29 & 0 & 0.00 & 0.00 \\
\hline$n$ of Segments & & & & 18 & & & 10 & & \\
\hline$n$ of Claims & & & & 14 & & & 4 & & \\
\hline \multicolumn{10}{|l|}{ Chile } \\
\hline $\begin{array}{l}\text { Invalid and } \\
\text { Unreliable }\end{array}$ & & & & 20 & 64.52 & 100 & 0 & 0 & 0 \\
\hline $\begin{array}{l}\text { Valid and } \\
\text { Reliable }\end{array}$ & & & & 0 & 0.00 & 0.00 & 15 & 88.24 & 100 \\
\hline$n$ of Segments & & & & 31 & & & 17 & & \\
\hline$n$ of Claims & & & & 20 & & & 15 & & \\
\hline
\end{tabular}

Table 7

Frequency and Percentage of Justification of Knowledge per Website

\begin{tabular}{lcccccccccccccc}
\hline & \multicolumn{4}{c}{ North America } & \multicolumn{4}{c}{ Japan } & \multicolumn{3}{c}{ Chile } \\
\hline & \multicolumn{1}{c}{ Balanced } & $\begin{array}{c}\text { Anti- } \\
\text { Vaccination }\end{array}$ & $\begin{array}{c}\text { Pro- } \\
\text { Vaccination }\end{array}$ & $\begin{array}{c}\text { Anti- } \\
\text { Vaccination }\end{array}$ & $\begin{array}{c}\text { Pro- } \\
\text { Vaccination }\end{array}$ & $\begin{array}{c}\text { Anti- } \\
\text { Vaccination }\end{array}$ & $\begin{array}{c}\text { Pro- } \\
\text { Vaccination }\end{array}$ \\
\hline & $f$ & $\%$ & $f$ & $\%$ & $f$ & $\%$ & $f$ & $\%$ & $f$ & $\%$ & $f$ & $\%$ & $f$ & $\%$ \\
\hline Authority & 59 & 88.06 & 0 & 0 & 17 & 100 & 8 & 80.00 & 0 & 0 & 0 & 0 & 12 & 100 \\
$\begin{array}{l}\text { Personal/ } \\
\text { Anecdotal }\end{array}$ & 8 & 11.94 & 5 & 100 & 0 & 0.00 & 2 & 20.00 & 0 & 0 & 0 & 0 & 0 & 0 \\
No support & 0 & 0 & 0 & 0 & 0 & 0 & 0 & 0 & 4 & 100 & 14 & 100 & 0 & 0 \\
$n$ & 67 & & 5 & & 17 & & 10 & & 4 & & 14 & & 12 & \\
\hline
\end{tabular}


Figure 1. Scores on certainty of knowledge as a function of culture and website.

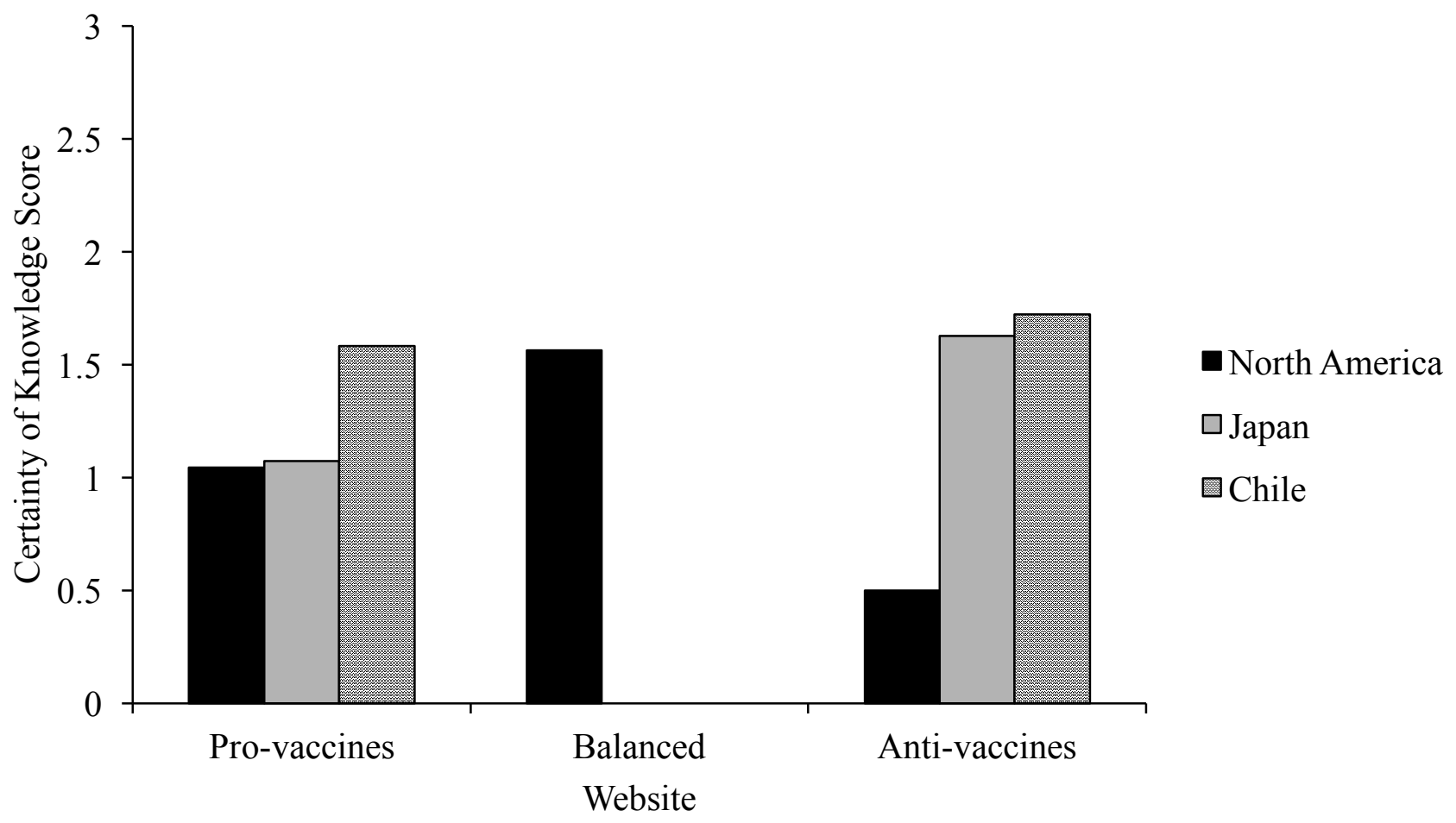

Figure 2. Scores on simplicity of knowledge as a function of culture and attitude.

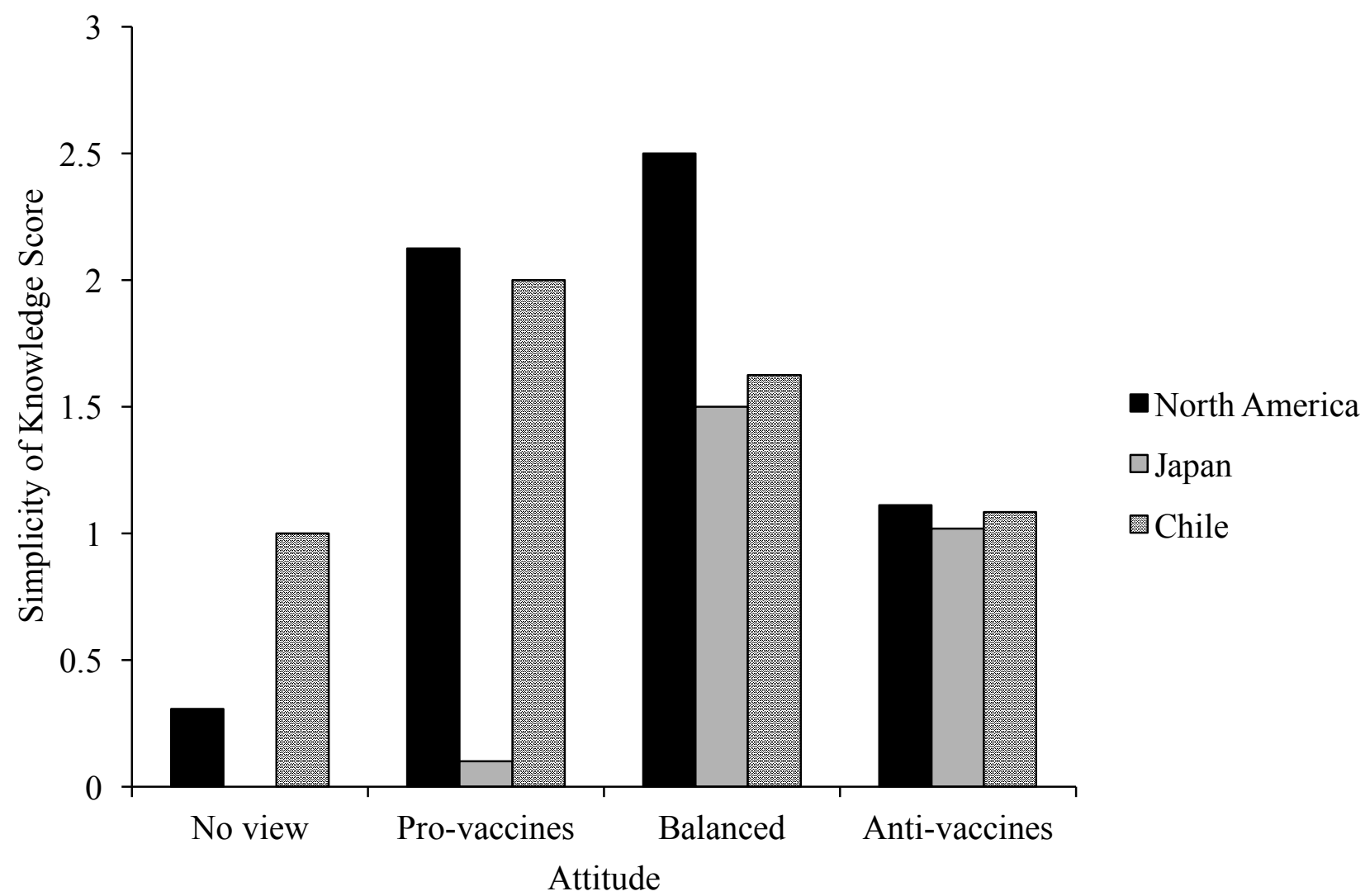

